\title{
Renal and Intestinal Handling of Oxalate following Oxalate Loading in Rats
}

\author{
Marguerite Hatch Robert W. Freel \\ Department of Pathology, Immunology and Laboratory Medicine, College of Medicine, University of Florida, \\ Gainesville, Fla., USA
}

\author{
Key Words \\ Hyperoxaluria. Hyperoxalemia - Renal failure. \\ Angiotensin II - Losartan · Distal colon · Chloride . \\ Transport
}

\begin{abstract}
Background: The enteric excretion of oxalate has been established in rats with chronic renal failure induced by 5/6 nephrectomy [Hatch et al.: Regulatory aspects of oxalate secretion in enteric oxalate elimination. JASN 1999;10:S324] and this response is mediated by angiotensin II receptor activation. However, the renal and intestinal handling of oxalate has not been evaluated for other common models of hyperoxaluria that simulate primary hyperoxaluria or oxalate stone disease. Methods: We assessed the renal clearances of creatinine, oxalate and calcium in three rat models: chronic hyperoxaluria $(\mathrm{CH})$, chronic hyperoxaluria with hyperoxalemia $(\mathrm{CHH})$ and acute hyperoxaluria $(\mathrm{AH})$, and evaluated the transepithelial transport of oxalate and chloride in large intestinal segments of these models and their sensitivity to angiotensin II antagonism. Results: Hyperoxaluria alone $(\mathrm{CH})$ was not associated with changes in colonic oxalate transport, whereas changes in net oxalate transport in distal colon from absorption to net secretion was observed in models with hyperoxalemia ( $\mathrm{CHH}$ and $\mathrm{AH})$. Angiotensin II receptor antagonism with losartan re-
\end{abstract}

\section{KARGER}

Fax + 41613061234

E-Mail karger@karger.ch

www.karger.com
(C) 2003 S. Karger AG, Basel

Accessible online at: www. karger.com/journals/ajn duced net colonic oxalate secretion in $\mathrm{AH}$ but not $\mathrm{CHH}$. Conclusions: Colonic secretion of oxalate is stimulated in rat models exhibiting hyperoxalemia suggesting a contribution of this extrarenal pathway to regulation of oxalate mass balance in clinical conditions manifesting hyperoxalemia. The transport avenues and regulatory mechanisms may not be identical to those observed during adaptive enteric oxalate secretion in chronic renal failure models.

Copyright @2003S. Karger AG, Basel

\section{Introduction}

The healthy kidney is the primary route for the excretion of oxalate, whether it is derived from dietary absorption or endogenous metabolism [1]. There is, however, a small amount of oxalate normally excreted by an enteric route which can be significantly enhanced when renal function is compromised $[2,3]$. Whereas the normal rat distal colon consistently supports a net absorptive flux of oxalate, this is reversed to net secretion in rats with chronic renal failure (CRF) induced by either 5/6 nephrectomy [3] or by chronic hyperoxaluria [4]. In addition, our previous studies implicated the involvement of angiotensin II (ANG II) in mediating this adaptive response in both CRF models [4, 5]. The notion that enteric handling of oxalate can participate in the mass balance of
Marguerite Hatch, $\mathrm{PhD}$

Department of Pathology, Immunology \& Laboratory Medicine

PO Box 100275, 1600 S.W. Archer Road

Gainesville, FL 32610 (USA)

Tel. +1 352 265 0111/ext. 72007, Fax +1 352392 3053, E-Mail hatchma@ufl.edu 
oxalate is further suggested by the fact that the magnitude and direction of oxalate transport across intestinal epithelia can be regulated [6-8]. Thus, it appears that oxalate excretion is balanced between the renal and enteric routes depending upon the degree of renal sufficiency. It is less clear how these two excretory routes are coordinated, if at all, in the context of various oxalate-associated diseases such as in primary hyperoxaluria or oxalate stone formation. In this report we present results of experiments designed to examine both colonic and renal handling of oxalate in several rat models that simulate some of the clinical characteristics of the oxalate-associated diseases.

\section{Materials and Methods}

\section{Animal Models}

Male Sprague-Dawley rats $(\sim 300 \mathrm{~g})$ were used in these studies. Since hyperoxaluria and oxalate stones can be initiated by feeding oxalate salts in the food, administering ethylene glycol in the drinking water, or by an intraperitoneal injection of oxalate [9], we divided rats into these three treatment groups. Untreated rats served as controls. The rats had free access to drinking water that was untreated or treated with ethylene glycol and with unlimited access to Purina rat chow 5001. The chronic hyperoxaluric $(\mathrm{CH})$ model had a specialized diet to include oxalate (see below). At the end of the specified treatment, prior to collecting blood and colonic tissues for the flux studies, urine from all rats was collected into vessels containing $3 \mathrm{ml}$ of $3.5 \mathrm{~N}$ $\mathrm{HCl}$ over a period of $24 \mathrm{~h}$. In the acute hyperoxaluric ( $\mathrm{AH}$ ) group, urine was collected directly from the bladder, using a syringe, at the time the rats were killed for the flux studies. At the end of each treatment regimen, the animals were euthanized by an intraperitoneal injection of sodium pentobarbital $(150 \mathrm{mg} / \mathrm{kg})$ and promptly exsanguinated by cardiac puncture. The blood was handled immediately with the appropriate precautions to prevent oxalogenesis [10]. Oxalate was measured in plasma and urine using an enzymatic assay procedure routine in our laboratory $[10,11]$. Creatinine and calcium were determined in the urine and plasma samples using the Sigma kit assay 555A and Sigma kit assay 587-A, respectively (Sigma Chemical Co., St. Louis, Mo., USA).

The rat models were developed as follows: (1) Chronic hyperoxaluria $(\mathrm{CH})$ without hyperoxalemia was produced in rats by feeding oxalate in a low $\mathrm{Ca}^{2+}$ diet for a 3-week period. A powdered diet containing $0.01 \% \mathrm{Ca}^{2+}$ (Product No. TD 99354, Harlan-Teklad, Madison, Wisc., USA) was supplemented with ammonium oxalate $(0.5 \%)$ and thoroughly mixed into batches before lightly wetting the mixture and rolling it into balls. The food balls were dried at room temperature and then placed in the rat cages. (2) Chronic hyperoxaluria and hyperoxalemia $(\mathrm{CHH})$ were induced in rats by adding $0.75 \%$ ethylene glycol to their drinking water for a period of 4 weeks. This regimen has been documented to produce persistent calcium oxalate crystalluria by day 7 and nephrolithiasis by $2-3$ weeks [9]. (3) Acute hyperoxaluria $(\mathrm{AH})$ was induced in rats by administering an intraperitoneal injection of sodium oxalate ( $3 \mathrm{mg} / 100 \mathrm{~g}$ body weight). Tissues were removed from this group $6 \mathrm{~h}$ after the injection for the flux studies since Khan [9] reported that urinary oxalate excretion is maximal at this time.

Renal and Intestinal Oxalate Excretion in

Rats

\section{Flux Studies}

Immediately following euthanasia and exsanguination of the rats, the proximal and distal colonic segments were removed, cleansed in ice-cold saline and partially stripped of the serosal muscularis. Flat sheets of tissue were mounted in modified Ussing chambers with an exposed tissue area of $0.64 \mathrm{~cm}^{2}$. Transepithelial fluxes of oxalate and chloride were measured using ${ }^{14} \mathrm{C}$-oxalate and ${ }^{36} \mathrm{Cl}$ across colonic tissues bathed on both sides by $10 \mathrm{ml}$ of buffered saline $(\mathrm{pH} 7.4)$ at $37^{\circ} \mathrm{C}$ circulated by bubbling with $95 \% \mathrm{O}_{2} / 5 \% \mathrm{CO}_{2}$. The standard saline contained the following solutes (mmol/l): $139.4 \mathrm{Na}^{+}, 5.4 \mathrm{~K}^{+}$, $1.2 \mathrm{Mg}^{2+}, 123.2 \mathrm{Cl}^{-}, 21.0 \mathrm{HCO}_{3}^{-}, 1.2 \mathrm{Ca}^{2+}, 0.6 \mathrm{H}_{2} \mathrm{PO}_{4}^{-}, 2.4 \mathrm{HPO}^{2-}$, and 10 glucose. The magnitude and direction of the net flux $\left(\mathrm{J}_{\mathrm{Net}}\right)$ was determined by calculating the difference between two unidirectional fluxes (mucosal to serosal, $\mathbf{J}_{\mathrm{ms}}$ and serosal to mucosal, $\mathbf{J}_{\mathrm{sm}}$ ) measured for a control period of $45 \mathrm{~min}$ (Per I) at 15-min intervals, under shortcircuit conditions. Per I was followed by a second 45-min flux period (Per II) in order to determine either time-dependent effects, or effects of drug (losartan, at $10^{-3} \mathrm{M}$ ) addition. The electrical parameters of the tissue were also recorded at 15 -min intervals throughout the entire experiment. Tissue conductance $\left(\mathrm{G}_{\mathrm{T}}, \mathrm{mS} \cdot \mathrm{cm}^{-2}\right)$ was calculated as the ratio of the open-circuit potential $(\mathrm{mV})$ to the shortcircuit current $\left(\mathrm{I}_{\mathrm{sc}}, \mu \mathrm{A} \cdot \mathrm{cm}^{-2}\right) .{ }^{14} \mathrm{C}$-oxalate and ${ }^{36} \mathrm{Cl}$ were obtained from New England Nuclear (Boston, Mass., USA). The $\mathrm{AT}_{1}$ receptor antagonist, losartan, was a gift from Merck \& Co., Inc. (Rahway, N.J., USA), and all other reagents were purchased from Sigma Chemical Co.

\section{Statistical Analysis}

Statistical analysis of the data derived from these experiments was performed by using a one-way analysis of variance (ANOVA) followed by Bonferroni's $t$ test for multiple comparisons with the control group. A paired or unpaired t test was used for the comparison of two means. Differences were considered significant if $\mathrm{p} \leq 0.05$.

\section{Results}

\section{Plasma Solute Concentrations and Renal Excretion}

The results presented in figure 1 provide a comparison of plasma solute concentrations and urinary solute excretion in all groups. Creatinine measurements were used to provide an index of renal function in these different animal groups and calcium measurements were included to evaluate the effects of oxalate loading on this important stone-risk factor. Renal handling of oxalate is characterized here using plasma and urinary measurements and standard calculations for renal solute clearances. As mentioned in the Methods section, 24-hour urinary solute excretion and renal clearances were not determined in the $\mathrm{AH}$ group, but these parameters are presented for the other groups and controls.

It is apparent that plasma creatinine, urinary creatinine excretion and clearance in both $\mathrm{CH}$ and $\mathrm{CHH}$ rats were not significantly different from control. These results suggest that renal function was unaffected by the 

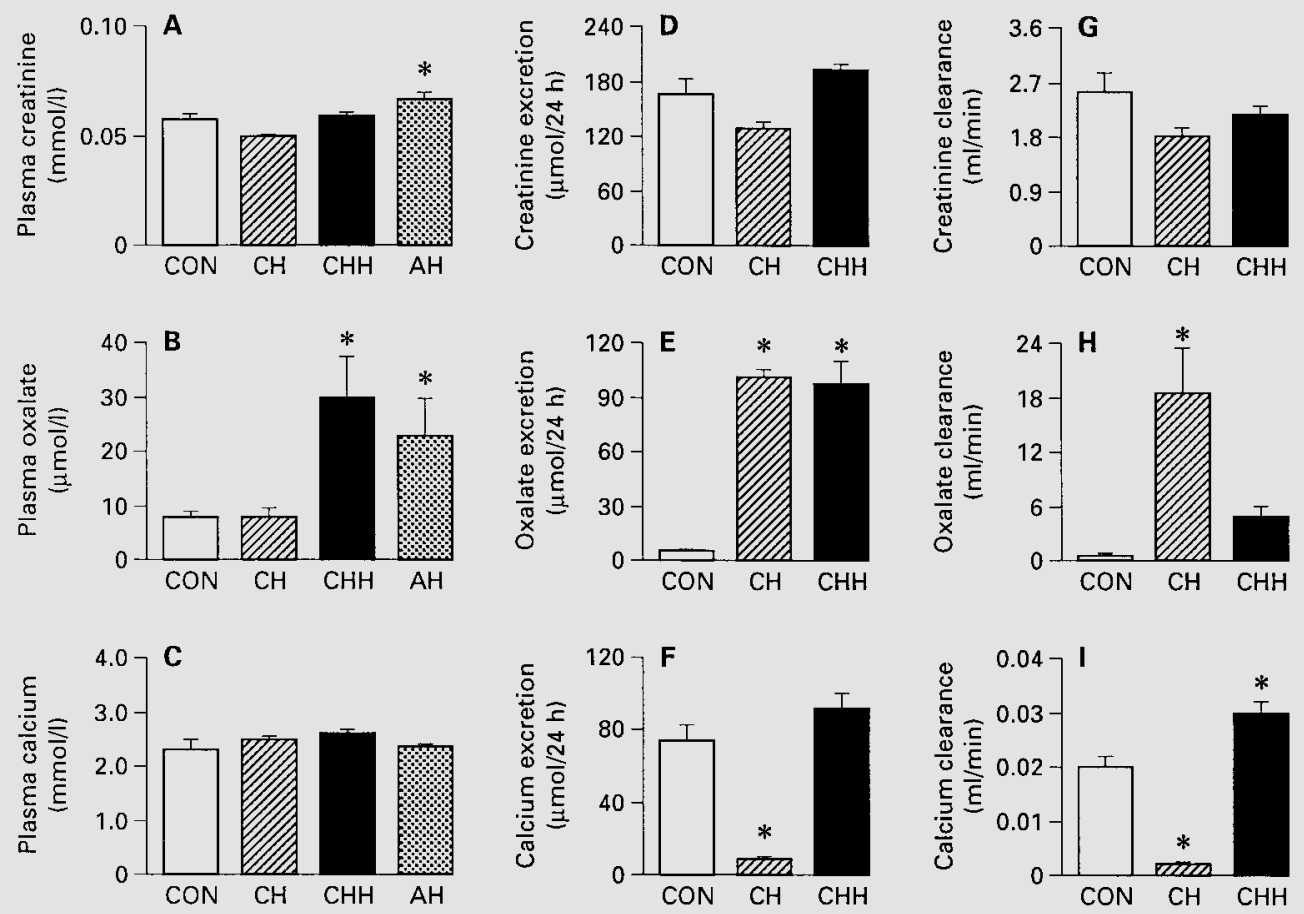

Fig. 1. Comparison of the plasma concentrations (A-C), the renal excretion (D-F) and the renal clearances (G-I) of creatinine, calcium and oxalate in several models of oxalate loading in rats. Normal controls $(\mathrm{CON}, \mathrm{n}=18)$, chronic hyperoxaluria $(\mathrm{CH}, \mathrm{n}=7)$, chronic hyperoxaluria with hyperoxalemia $(\mathrm{CHH}, \mathrm{n}=16)$ and acute hyperoxaluria $(\mathrm{AH}$, $\mathrm{n}=11$ ) models were generated as described in Materials and Methods. Error bars represent $1 \mathrm{SE}$ of the mean for each group and an asterisk indicates a significant difference from the control group as judged by a one-way ANOVA followed by Bonferroni's $t$ test with $\mathrm{p} \leq 0.05$.

oxalate loads delivered to these two groups. In contrast, a small but significant increase in plasma creatinine occurred in the AH group indicating some degree of renal dysfunction.

\section{Oxalate Handling}

Of the three oxalate-loaded groups examined, plasma oxalate concentration was found normal in $\mathrm{CH}$ rats, but significantly elevated in both $\mathrm{CHH}$ and $\mathrm{AH}$ compared to control. As expected, urinary oxalate excretion was markedly elevated in all of the treated groups. In the AH group, the magnitude of hyperoxaluria was estimated by measuring oxalate $(\mu \mathrm{mol} / \mathrm{l})$ in the variable, small volumes of urine retrieved from each rat bladder at the time of euthanasia. Urinary oxalate was standardized per unit of creatinine $(\mu \mathrm{mol} / \mathrm{l})$ that was also measured in the same bladder urine specimen. A group of rats injected with isotonic saline served as controls. This excretion ratio (oxalate/creatinine) determined in the $\mathrm{AH}$ rats $(\mathrm{n}=11)$ increased about 9-fold to $230 \pm 130$ from a value of $26 \pm 2$ which was determined from the paired controls $(n=9)$ injected with saline. The results also show that the renal clearance of oxalate was markedly increased in $\mathrm{CH}$ by 28 -fold compared to control. However, despite a 7-fold increase in renal clearance of oxalate in $\mathrm{CHH}$, this did not reach statistical significance. Finally, clearance ratios (oxalate/creatinine) that are significantly greater than unity in $\mathrm{CH}$ $(10.2 \pm 1.2, \mathrm{n}=7)$ and $\mathrm{CHH}(2.1 \pm 0.5, \mathrm{n}=16)$ rats indicate varying degrees of tubular oxalate secretion in both hyperoxaluric groups compared to apparent tubular reabsorption in the controls $(0.5 \pm 0.1, \mathrm{n}=18)$. 


\section{Calcium Handling}

No differences in plasma calcium concentrations were observed in any of the treated groups compared to control, however, renal handling of calcium was altered to varying degrees. A significant reduction in urinary calcium excretion was evident in the $\mathrm{CH}$ group which was most likely due to the low calcium content of the oxalatesupplemented diet. In AH rats, urinary calcium excretion was also reduced by about $50 \%$. This decrease was similarly determined in bladder urine removed from the $\mathrm{AH}$ group as described above for oxalate. (Urinary calcium was standardized per unit of creatinine $(\mu \mathrm{mol} / \mathrm{l})$ measured in the same bladder urine specimen from $\mathrm{AH}$ and rats injected with isotonic saline.) The mean urinary excretion ratio (calcium/creatinine) determined in the $\mathrm{AH}$ rats $(\mathrm{n}=$ 11) decreased to $0.22 \pm 0.04$ from a value of $0.43 \pm 0.06$ determined in the paired controls $(n=9)$. Urinary calcium excretion in $\mathrm{CHH}$ rats was not significantly different compared to controls. It is also apparent that renal clearance of calcium is markedly reduced in $\mathrm{CH}$ rats. A calculation of renal clearance ratios (calcium/creatinine) for the control, $\mathrm{CH}$ and $\mathrm{CHH}$ groups revealed a significant difference between $\mathrm{CH}(0.001 \pm 0.0001, \mathrm{n}=7)$ and no difference between $\mathrm{CHH}(0.01 \pm 0.002, \mathrm{n}=16)$ when compared with control $(0.01 \pm 0.001, \mathrm{n}=18)$. Again, it is likely that the low calcium content of the diet explains the significant reductions in renal calcium excretion and clearance in the $\mathrm{CH}$ group.

\section{Colonic Oxalate Transport}

Our previous studies have shown that enteric excretion of oxalate is induced in CRF rats and that this adaptation involves local ANG II mediation [4, 5]. These studies prompted the question of whether colonic transport of oxalate is altered in oxalate-loaded rats with or without renal dysfunction. The question of whether changes in oxalate fluxes, if any, involve ANG II was also addressed in the following experiments. In all of these experimental series using proximal and distal colon, the results presented were acquired during Per I. Results acquired during Per II showed there were no significant time-dependent changes in either the fluxes or the associated electrical parameters in any series over the duration of the two flux periods (data not shown).

Oxalate fluxes across the distal colon removed from rats in the three oxalate-loaded groups are compared to control fluxes in figure 2. The results show that control rats (including rats injected with saline) and $\mathrm{CH}$ rats, support a net absorptive flux of oxalate of comparable magnitude. In contrast, coordinated changes in the unidirec-

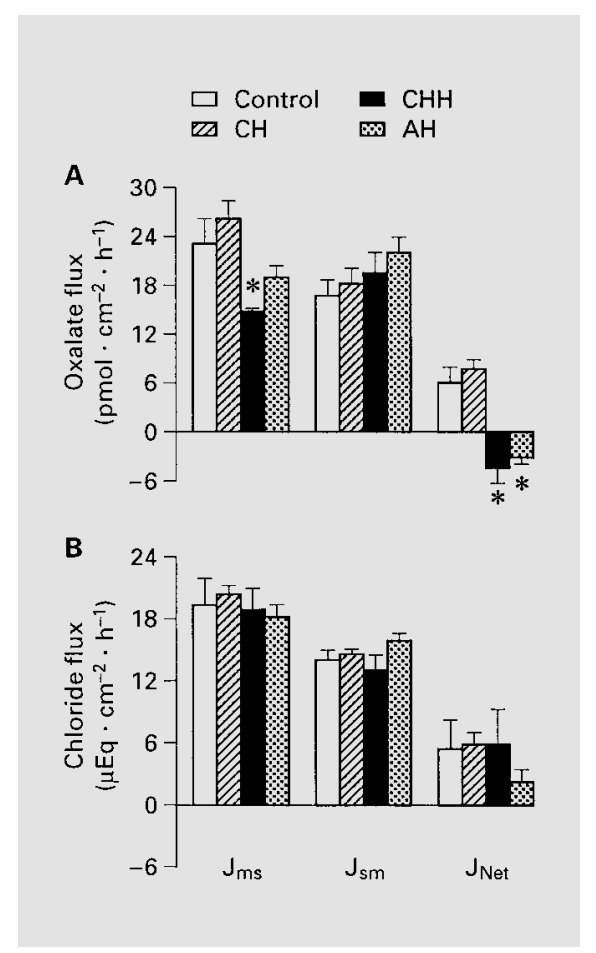

Fig. 2. Unidirectional and net transepithelial fluxes of oxalate (A) and chloride (B) across isolated, short-circuited segments of the distal colon from several rat models of oxalate loading. Control $(\mathrm{CON}, \mathrm{n}=$ $6)$, chronic hyperoxaluria $(\mathrm{CH}, \mathrm{n}=7)$, chronic hyperoxaluria with hyperoxalemia $(\mathrm{CHH}, \mathrm{n}=8)$ and acute hyperoxaluria $(\mathrm{AH}, \mathrm{n}=11)$ models were generated as described in Materials and Methods. The number of tissue pairs is represented by n. Error bars represent $1 \mathrm{SE}$ of the mean for each group and an asterisk indicates a significant difference from the control group as judged by a one-way ANOVA followed by Bonferroni's $t$ test with $p \leq 0.05$. None of the oxalateloading regimens significantly changed $\mathrm{I}_{\mathrm{sc}}$ or $\mathrm{G}_{\mathrm{T}}$ from control values of $4.3 \pm 0.4 \mu \mathrm{Eq} \cdot \mathrm{cm}^{-2} \cdot \mathrm{h}^{-1}$ and $9.8 \pm 0.6 \mathrm{mS} \cdot \mathrm{cm}^{-2}$, respectively.

tional fluxes of oxalate resulted in a significant net secretion of oxalate across colonic tissues removed from $\mathrm{AH}$ and $\mathrm{CHH}$ rats. These changes in oxalate transport were not accompanied by changes in $\mathrm{Cl}^{-}$transport and there were no alterations in the associated electrical characteristics.

Whereas the distal colon supports net oxalate and $\mathrm{Cl}^{-}$ absorption, we have observed that the proximal colon supports a basal net secretory flux of both anions [6] and these results are confirmed here (fig. 3). It is also apparent that there are no significant alterations in either oxalate or $\mathrm{Cl}^{-}$transport across this segment in any of the treated groups. 


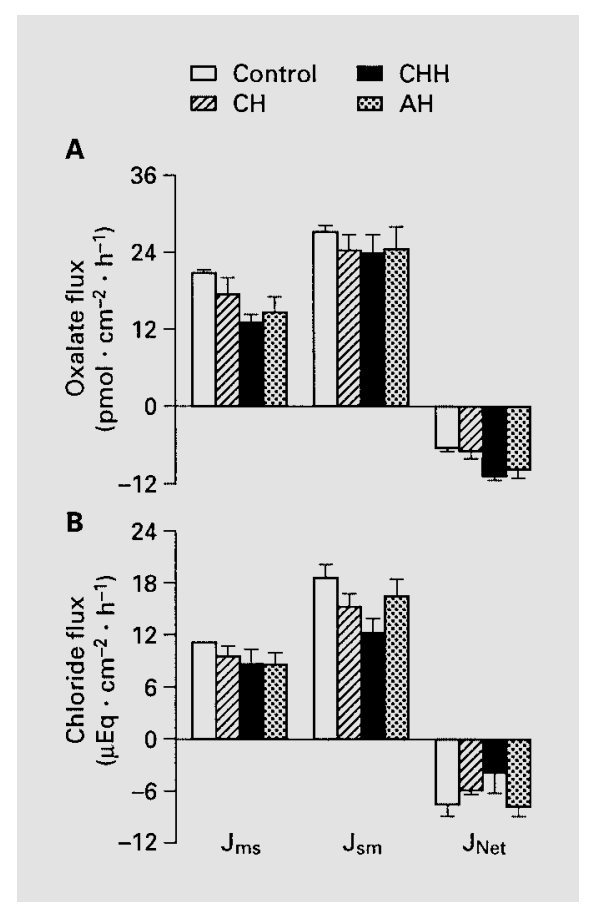

Fig. 3. Unidirectional and net transepithelial fluxes of oxalate (A) and chloride (B) across isolated, short-circuited segments of the proximal colon from several rat models of oxalate loading. Control (CON, $\mathrm{n}=5)$, chronic hyperoxaluria $(\mathrm{CH}, \mathrm{n}=6)$, chronic hyperoxaluria with hyperoxalemia $(\mathrm{CHH}, \mathrm{n}=8)$ and acute hyperoxaluria $(\mathrm{AH}, \mathrm{n}=6)$ models were generated as described in Materials and Methods. The number of tissue pairs is represented by n. Error bars represent $1 \mathrm{SE}$ of the mean for each group and an asterisk indicates a significant difference from the control group. None of the oxalate-loading regimens significantly affected oxalate or chloride transport in the rat proximal colon as judged by a one-way ANOVA followed by Bonferroni's $t$ test with $\mathrm{p} \leq 0.05$. Similarly, $\mathrm{I}_{\mathrm{sc}}$ and $\mathrm{G}_{\mathrm{T}}$ of the treated groups were unchanged from control values of $2.2 \pm 0.3 \mu \mathrm{Eq} \cdot \mathrm{cm}^{-2} \cdot \mathrm{h}^{-1}$ and $15.5 \pm 4.2 \mathrm{mS} \cdot \mathrm{cm}^{-2}$, respectively.

\section{Effects of Losartan on Colonic Anion Transport in CHH and AH Rats}

As mentioned above, we have shown that net oxalate secretion in CRF distal colon is partly mediated by $\mathrm{AT}_{1}$ receptor agonism based upon a sensitivity to losartan [4, 5]. We have also observed that basal oxalate secretion in the proximal colon of control rats is insensitive to losartan (data not shown). Consequently, in the next series, we examined the effects of losartan on oxalate secretion that was manifest only in $\mathrm{CHH}$ and $\mathrm{AH}$ distal colonic segment. As shown in figure 4, losartan addition, at a concentration $\left(10^{-3} M\right)$ known to have a maximum inhibitory effect on $\mathrm{Cl}^{-}$transport across this tissue preparation [12],

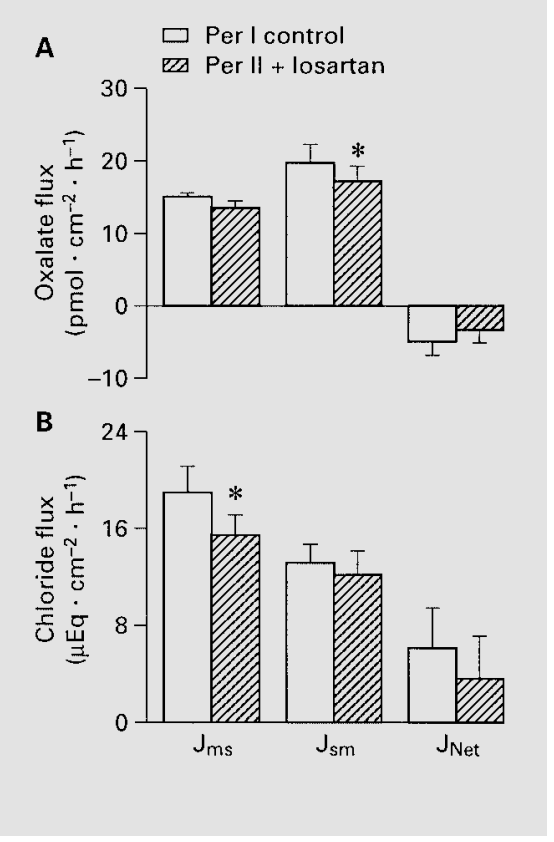

Fig. 4. Effects of ANG II receptor antagonism on the unidirectional and net transepithelial fluxes of oxalate $(\mathbf{A})$ and chloride (B) across isolated, short-circuited segments of the distal colon from the chronic hyperoxaluria with hyperoxalemia $(\mathrm{CHH}, \mathrm{n}=8)$ rat model. For each tissue pair control fluxes (open boxes) were established in Per I after which losartan was added $\left(10^{-3} \mathrm{M}\right.$, final concentration) to the serosal sides of the tissues. Period II (hatched boxes) represents flux measurements following losartan addition. The number of tissue pairs is represented by $n$. Error bars represent $1 \mathrm{SE}$ of the mean and an asterisk indicates a significant difference from Per I as judged by Student's t test with $\mathrm{p} \leq 0.05$. Losartan did not significantly alter $\mathrm{G}_{\mathrm{T}}$ from control values $10.7 \pm 0.7 \mathrm{mS} \cdot \mathrm{cm}^{-2}$, but $\mathrm{I}_{\mathrm{sc}}$ was significantly reduced by this ANG II receptor antagonist (from control values of $5.5 \pm 0.7$ to $\left.4.2 \pm 0.6 \mu \mathrm{Eq} \cdot \mathrm{cm}^{-2} \cdot \mathrm{h}^{-1}\right)$.

had no significant effect on the net flux of oxalate in $\mathrm{CHH}$ despite a small but significant reduction in the secretory component $\left(\mathrm{J}_{\mathrm{sm}}^{\mathrm{OX}}\right)$ of the net flux. These results suggest that net oxalate secretion stimulated in the $\mathrm{CHH}$ model is not primarily dependent upon $\mathrm{AT}_{1}$ agonism. In contrast, net oxalate secretion in $\mathrm{AH}$ distal colon (fig. 5) was abolished by losartan addition, albeit a net absorptive flux was not fully restored as we have seen before in CRF rat models $[4,5]$. The changes in $\mathrm{Cl}^{-}$fluxes following losartan are entirely consistent with what we have previously observed in chloride-absorbing tissues, namely reductions in unidirectional fluxes with no significant alteration in the net flux [12]. Tissue conductance was not altered in any series 


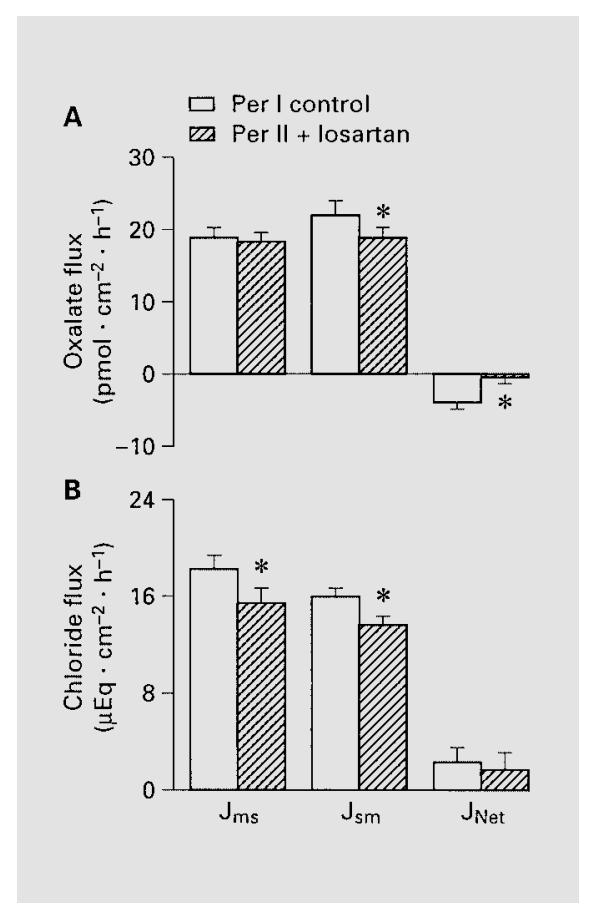

Fig. 5. Effects of ANG II receptor antagonism on the unidirectional and net transepithelial fluxes of oxalate (A) and chloride (B) across isolated, short-circuited segments of the distal colon from the acute hyperoxaluria $(\mathrm{AH}, \mathrm{n}=8)$ rat model. For each tissue pair control fluxes (open boxes) were established in Per I after which losartan was added $\left(10^{-3} M\right)$ to the serosal sides of the tissues. Period II (hatched boxes) represents flux measurements following losartan addition. The number of tissue pairs is represented by n. Error bars represent \pm 1 SE of the mean and an asterisk indicates a significant difference from Per I as judged by Student's t test with $p \leq 0.05$. Losartan addition did not significantly change $\mathrm{I}_{\mathrm{sc}}$ or $\mathrm{G}_{\mathrm{T}}$ in the $\mathrm{AH}$ rats from control values of $4.7 \pm 0.4 \mu \mathrm{Eq} \cdot \mathrm{cm}^{-2} \cdot \mathrm{h}^{-1}$ and $11.4 \pm 0.5 \mathrm{mS} \cdot \mathrm{cm}^{-2}$, respectively.

presented in figures 4 and 5 but the reduction noted in $\mathrm{I}_{\mathrm{sc}}$ across $\mathrm{CHH}$ tissues (fig. 4, legend) suggests that losartan had an affect on the electrogenic movement of some ion, other than chloride.

\section{Discussion}

Previous studies have demonstrated that enteric secretion of oxalate provides an additional excretory route which becomes important when renal function declines $[2,3]$. The present study addressed the question of how the renal and enteric routes of oxalate elimination are coordinated in rats following an oxalate load. In the following discussion it is important to note that the magni- tude of the oxalate challenges presented to the kidneys of these rats was likely different among the experimental groups because the systemic oxalate load was derived in a different way in each model. For example, a calculation, based upon a minimum (10\%) conversion of ethylene glycol to oxalate, would suggest that the oxalate load delivered to the $\mathrm{CHH}$ rat was at least 10 -fold smaller than that delivered to the $\mathrm{AH}$ rat. We also acknowledge that the rate of diffusion of the load injected into the peritoneal cavity will impact the amount of oxalate challenging the kidneys at any one point in time. In the $\mathrm{CH}$ group, dietary oxalate absorption was undoubtedly a limiting factor in the magnitude of the oxalate load presented to the kidneys in this model. It was also apparent that this latter group sustained normal plasma oxalate levels and normal renal function with maximal urinary oxalate excretion at least for the duration of the study. Certainly, the time course of the various regimens differs and in this context we note that the AH group, in particular, is not a 'steady-state' model. There is also a temporal component that is associated with the duration of chronic hyperoxaluria, since we have observed that $(\mathrm{CH})$ rats maintained on the dietary oxalate-loading regimen for an extended period $(>3$ weeks), exhibit a reduction in renal function [unpubl. data]. Renal function in ethylene glycol $(0.75 \%)$-treated rats can apparently remain unaltered for many weeks/ months despite chronic hyperoxaluria [unpubl. data] and despite renal damage as indicated by significant lipid peroxide production as early as the 15th day of treatment [13].

\section{Renal Handling of Oxalate}

Although urinary oxalate excretion was increased in all oxalate-loaded groups, renal function (as judged by creatinine clearance and/or plasma creatinine) appeared to be reduced only in $\mathrm{AH}$ rats. The small but significant increase in plasma creatinine in this group cannot be explained by the degree of hyperoxaluria induced ( 9 times), given this was even greater in $\mathrm{CHH}$ rats (16 times) whose renal function was found to be normal. In addition, plasma oxalate in both groups was comparably elevated. One possible explanation may be that the acute oxalate load delivered intraperitoneally presents a larger oxalate challenge, and is immediately more damaging to renal function than a load derived gradually from systemic metabolism of ethylene glycol. Severe renal damage due to calcium oxalate crystallization has been well documented in this acute model using larger injected doses [14]. However, at this low dosage of $3 \mathrm{mg} / 100 \mathrm{~g}$ body weight, Khan et al. reported no evidence of renal damage 
as judged by urinary creatinine excretion and urinary enzyme markers $6 \mathrm{~h}$ after injection, but plasma creatinine concentrations were not determined. In another oxalateloaded model, Kumar et al. [15] did report significant increases in urinary enzyme markers, indicative of renal injury, which was not accompanied by alterations in urinary creatinine excretion but, again, plasma creatinine concentrations were not reported. It is notable here that we have shown that creatinine clearance can be significantly reduced in rats with no significant change in urinary creatinine excretion achieved under 'steady-state' conditions $[3,12,16]$.

Many studies examining renal excretion of oxalate by humans and animals have relied upon oxalate/creatinine clearance ratios to indicate either tubular secretion (clearance ratios $>1$ ) or tubular reabsorption (clearance ratios $<1$ ) of oxalate. Such studies have demonstrated that clearance ratios can range from mean values between 0.4 and 2.0 in healthy individuals as well as in stone-forming patients [17-27], with considerable overlap of values when all studies and both groups are considered. In general, the oxalate/creatinine ratio is elevated (ratio $\sim 3$ ) in patients with primary hyperoxaluria $[17,18,20]$ compared to controls. Studies that we have conducted, examining oxalate and creatinine clearances in humans [24, 28] and rats [3], have revealed oxalate/creatinine clearance ratios that are similar and $<1$ in controls of both species. These observations are confirmed in the present study for the controls. In addition, the capacity of the kidney to secrete oxalate was evident in all of the oxalate challenged groups here. The marked increase in both renal clearance (28 times) and the clearance ratio (19 times) in the $\mathrm{CH}$ group would suggest that the capacity of the healthy kidney to excrete oxalate is considerably greater than previously thought. Although a significant renal secretion of oxalate also occurred in the $\mathrm{CHH}$ rats, it is nonetheless curious that renal clearance of oxalate and the estimate of the secretory capacity (i.e. the oxalate/creatinine clearance ratio), are 4- and 5-fold less, respectively, in this group when compared to $\mathrm{CH}$ (these differences are statistically significant). The reason for this is unclear since renal function and the degree of hyperoxaluria are comparable in both groups. What is different between the two groups is plasma oxalate concentration which is normal in $\mathrm{CH}$ and elevated approximately 4 -fold in $\mathrm{CHH}$. A further difference between these groups is adaptive enteric oxalate secretion which is induced in the distal colon of $\mathrm{CHH}$ but not in $\mathrm{CH}$ rats, and this is discussed below.

\section{Calcium}

The oxalate-loading regimens used in the present study had no effect on plasma calcium homeostasis but there were some effects on renal calcium handling. It was expected to find that renal excretion and clearance of calcium were markedly reduced in the $\mathrm{CH}$ group, since the diet fed to these rats contained $0.01 \%$ calcium compared to a calcium content of $0.95 \%$ in the rat chow fed to the control, $\mathrm{CHH}$ and $\mathrm{AH}$ rats. This oxalate-supplemented diet was purposely designed with low calcium content to promote optimal bioavailability and oxalate absorption along the intestinal tract in order to induce hyperoxaluria. In contrast, the $50 \%$ reduction in renal excretion of calcium in the AH group was unexpected. While the reasons for this are unclear, one possibility may be that chelation of calcium and renal/extrarenal tissue deposition of calcium oxalate following the acute, massive oxalate load provide for a calcium sink thereby reducing urinary calcium excretion. Indeed, a cursory examination of the kidneys from these rats did reveal obvious deposition both externally and internally but we did not conduct an examination of any other organs or tissues. In contrast to these results in $\mathrm{AH}$, we found that gradual oxalate loading via ethylene glycol treatment did not reduce urinary calcium excretion. In fact, the small but significant increase in renal clearance of calcium in these rats suggested a possible reduction in tubular calcium reabsorption, but, this was not reflected by a change in the mean clearance ratio (calcium/creatinine) of this group when compared to control.

\section{Enteric Oxalate Handling}

The results of the colonic transport studies indicate that hyperoxaluria, per se, does not appear to induce alterations in colonic oxalate handling. Colonic transport of oxalate in $\mathrm{CH}$ rats was normal despite significant chronic hyperoxaluria. The results do indicate that adaptive enteric oxalate secretion can be correlated with elevations in plasma oxalate concentrations in the absence of overt renal insufficiency. This latter point is important because we had concluded from our prior studies that the reversal in the direction of net oxalate transport across the distal colon, from absorption to secretion, was correlated with some degree of renal insufficiency [3-5]. Previously, we demonstrated that adaptive enteric oxalate secretion/ excretion occurs in two different CRF rat models both exhibiting a 2-fold increase in plasma creatinine [3, 4]. Although urinary oxalate excretion was normal in one of these CRF models, both had elevated plasma oxalate concentrations. In the present study we found that colonic 
tissues from $\mathrm{AH}$ and $\mathrm{CHH}$ rats supported net oxalate secretion, both of these groups were hyperoxaluric with comparable hyperoxalemia, however, renal function was reduced in $\mathrm{AH}$ and normal in $\mathrm{CHH}$. Thus, in the rat models examined that exhibit adaptive enteric oxalate secretion, they have in common an elevation in plasma oxalate. This observation is supported by results from Costello et al. [2] who showed that percent fecal ${ }^{14} \mathrm{C}$-oxalate excretion was directly correlated with elevations in plasma oxalate in CRF. Results from the latter study which followed the distribution of tracer also showed that the percent of ${ }^{14} \mathrm{C}$-oxalate excreted in feces can account for up to $40 \%$ of the tracer burden. Therefore, it is conceivable that enteric elimination of oxalate could be significantly in excess of $40 \%$ of the oxalate load following the regimens described here. On the basis of this and the flux studies conducted here, we suggest that significant enteric elimination of oxalate in $\mathrm{CHH}$ and $\mathrm{AH}$ rats accounts for the $\sim 5$-fold difference in renal oxalate secretory capacity (i.e. as judged by mean oxalate/creatinine clearance ratios) when compared to $\mathrm{CH}$ rats.

\section{Effects of Losartan on Enteric Oxalate Secretion}

While enteric oxalate secretion/excretion was induced in $\mathrm{CHH}$ and $\mathrm{AH}$ rats, it appeared that there were some mechanistic differences between the two groups in how this secretory process was mediated. Net secretion of oxalate across the distal colon of $\mathrm{AH}$ rats was significantly reduced by $\mathrm{AT}_{1}$ receptor antagonism (losartan) and it remained unaltered in $\mathrm{CHH}$ rats following the same maneuver. Clearly, losartan addition to isolated AH distal colon did not completely reverse net secretion of oxalate to a net absorptive flux as we have seen before in CRF rats $[4,5]$. However, the significant reduction in both $\mathrm{J}_{\mathrm{sm}}^{\mathrm{OX}}$ and $\mathbf{J}_{\mathrm{Net}}^{\mathrm{OX}}$ in $\mathrm{AH}$ implicates the involvement of ANG II in mediating oxalate secretion. Although $\mathrm{J}_{\mathrm{sm}}^{\mathrm{OX}}$ was decreased in $\mathrm{CHH}$ distal colon, ANG II involvement in mediating enteric excretion of oxalate in $\mathrm{CHH}$ rats was not strongly indicated.

In summary, these results support the concept that oxalate elimination is balanced between the renal and excretory routes. We suggest that the capacity of the kidney to secrete oxalate may be considerably greater than previously thought. Several features of oxalate handling by the large intestine of oxalate-loaded rats emerged from this study: (1) The distal segment is the primary site for adaptive enteric oxalate elimination associated with elevations in plasma oxalate. (2) We observed, for the first time, that colonic oxalate and chloride secretion can be dissociated. (3) There are additional oxalate secretory pathways, independent of ANG II regulation and distinct from those electrogenic chloride secretory pathways previously implicated in oxalate secretion [7,29].

\section{Acknowledgements}

This work was supported in part by a grant from the Oxalosis and Hyperoxaluria Foundation and in part by NIH (R01 DK56245).

\section{References}

1 Elder TD, Wyngaarden JB: The biosynthesis and turnover of oxalate in normal and hyperoxaluric subjects. J Clin Invest 1960;39:13371344.

2 Costello JF, Smith M, Stolarski C, Sadovnic $\mathrm{MJ}$ : Extrarenal clearance of oxalate increases with progression of renal failure in the rat. $\mathrm{J}$ Am Soc Nephrol 1992;3:1098-1104.

3 Hatch M, Freel RW, Vaziri ND: Intestinal excretion of oxalate in chronic renal failure. $\mathrm{J}$ Am Soc Nephrol 1994;5:1339-1343.

4 Hatch M, Freel RW: Adaptive enteric oxalate excretion in chronic renal failure induced by hyperoxaluria; in Proc 9th International Symposium on Urolithiasis, Cape Town 2000.

5 Hatch M, Freel RW, Vaziri ND: Regulatory aspects of oxalate secretion in enteric oxalate elimination. J Am Soc Nephrol 1999;10:S324S328.

Renal and Intestinal Oxalate Excretion in Rats
6 Hatch M, Freel RW, Vaziri ND: Characteristics of the transport of oxalate and other ions across rabbit proximal colon. Pflügers Arch 1993;423:206-212.

7 Hatch M, Freel RW, Vaziri ND: Mechanisms of oxalate absorption and secretion across the rabbit distal colon. Pflügers Arch 1994;426: 101-109.

8 Hatch M, Freel RW: Alterations in intestinal transport of oxalate in disease states. Scanning Microsc 1995;9:1121-1126.

9 Khan SR: Animal models of calcium oxalate nephrolithiasis; in Khan SR (ed): Calcium Oxalate in Biological Systems. Boca Raton, CRC Press, 1995, pp 343-359.

10 Hatch M: Spectrophotometric determination of oxalate in whole blood. Clin Chim Acta 1990;193:199-202.

11 Costello J, Hatch M, Bourke E: An enzymic method for the spectrophotometric determination of oxalic acid. J Lab Clin Med 1976;87: 903-908.
12 Hatch M, Freel RW, Shahinfar S, Vaziri ND: Effects of the specific angiotensin II receptor antagonist losartan on urate homeostasis and intestinal urate transport. J Pharmacol Exp Ther 1996;276:187-193.

13 Thamilselvan S, Hackett RL, Khan SR: Lipid peroxidation in ethylene glycol induced hyperoxaluria and calcium oxalate nephrolithiasis. $\mathrm{J}$ Urol 1997;157:1059-1063.

14 Khan SR, Shevock PN, Hackett RL: Acute hyperoxaluria, renal injury and calcium oxalate urolithiasis. J Urol 1992;147:226-230.

15 Kumar S, Sigmon D, Miller T, Carpenter B, Khan S, Malhotra R, Scheid C, Menon M: A new model of nephrolithiasis involving tubular dysfunction/injury. J Urol 1991;146:13841389.

16 Hatch M, Vaziri ND: Enhanced enteric excretion of urate in rats with chronic renal failure. Clin Sci 1994;86:511-516. 
17 Wilson DM, Smith LH, Erickson SB, Torres VE, Liedtke RR: Renal oxalate handling in normal subjects and patients with idiopathic renal lithiasis: Primary and secondary hyperoxaluria. Urolithiasis. New York, Plenum Press, 1988.

18 Kasidas GP: Assaying of oxalate in plasma; in Oxalate Metabolism in Relation to Urinary Stone. Berlin, Springer, 1988, pp 45-64.

19 Gambaro G, Petrarulo M, Nardelotto A, Marangella $\mathrm{M}$, Baggio $\mathrm{B}$ : Erythrocyte transmembrane flux and renal clearance of oxalate in idiopathic calcium nephrolithiasis. Kidney Int 1995;48:1549-1552.

20 Kasidas GP, Nemat S, Rose GA: Plasma oxalate and creatinine and oxalate/creatinine clearance ratios in normal subjects and in primary hyperoxaluria. Evidence for renal hyperoxaluria. Clin Chim Acta 1990;191:67-77.
21 Schwille PO, Manoharan M, Rumenapf G, Wolfel G, Berens H: Oxalate measurement in the picomole range by ion chromatography: Values in fasting plasma and urine of controls and patients with idiopathic calcium urolithiasis. J Clin Chem Clin Biochem 1989;27:8796.

22 Hodgkinson A, Wilkinson R: Plasma oxalate concentration and renal excretion of oxalate in man. Clin Sci Mol Med 1974;46:61-73.

23 Prenen JA, Boer P, Mees EJ, Endeman HJ, Spoor SM, Oei HY: Renal clearance of $\left[{ }^{14} \mathrm{C}\right]$ oxalate: Comparison of constant-infusion with single-injection techniques. Clin Sci 1982;63: 47-51.

24 Hatch M, Schepers A, Grunberger I, Godec CJ: A retrospective analysis of the metabolic status of stone formers in the New York City metropolitan areas. N Y State J Med 1991;91:196200.
25 Sutton RA, Walker VR: Enteric and mild hyperoxaluria. Miner Electrolyte Metab 1994;20: 352-360.

26 Ogura H: Determinations of oxalate in urine and plasma by capillary electrophoresis. Nippon Hinyokika Gakkai Zasshi 2000;91:547555.

27 Pinto B, Crespi G, Sole-Balcells F, Barcelo P: Patterns of oxalate metabolism in recurrent oxalate stone formers. Kidney Int 1974;5:285291.

28 Hatch M: Oxalate status in stone-formers: Two distinct hyperoxaluric entities. Urol Res 1993; 21:55-59.

29 Freel RW, Hatch M, Vaziri ND: Conductive pathways for chloride and oxalate in rabbit ileal brush-border membrane vesicles. Am J Physiol 1998;275:C748-C757. 